\title{
Wyburn-Mason syndrome - A rare preventable cause of CV stroke in young.
}

\author{
Dr.Hetal Pandya ${ }^{1}$, Dr.Bhavesh Kansara ${ }^{2}$, Dr. Jaydutt Patel ${ }^{2}$, Dr. Som Lakhani ${ }^{3}$ \\ ${ }^{1}$ Proffessor Of Department Of Medicine, \\ ${ }^{2}$ Junior Resident. Department Of Medicine, \\ ${ }^{3}$ Assistant professor of Department of Skin and VD, S.B.K.S.M.I.R.C., Sumandeep Vidyapeeth, \\ Vadodara, Gujarat, India.
}

\begin{abstract}
:
Introduction : Wyburn-Mason syndrome is a rare condition considered as one of the nonhereditory congenital phacomatosis,characterised by arterio-venous malformations that affects retina,visualpathway, mid-brain and facial structures with no age and sex predilection.To the date, fewer than 100 cases have been reported in the literature ${ }^{l}$.so herein we are reporting a case of Wyburn-Mason syndrome.

Case report : A 22 years male,presented with acute onset of weakness in right upper and lower limb since 3 days,associated with right eye ptosis and deviation of angle of mouth to left.It was preceded by an episode of vomitting and generalised tonic clonic seizure .CT Brain revealed fresh haemorrhage in left Basal ganglia and $C T$ Angiography Brain revealed A-V malformation on left side.Fundus examination revealed venous dilatation with tortousity of vessels in left eye.Patient also had congenital port wine coloured skin lesion over right side of face not crossing midline.So in view of AVM involving brain,retina and facial structures, it was diagnosed as Wyburn-Mason syndrome.presenting as intracranial haemorrhage in young patient.

Conclusion : The presentation of patients with Wyburn-Mason syndrome can vary greatly according to site and extent of vascular lesions without age and sex predilection.The natural course of intracranial AVM's is poorly documented.However, they tend to be extensive and inaccessible.so early diagnosis is important preventive strategy.
\end{abstract}

Keywords : Wyburn-Mason syndrome, Arteriovenous malformations, Bonnet-Dechaume-Blanc syndrome

\section{Introduction}

Wyburn-Mason syndrome (WMS), also known as Bonnet-Dechaume-Blanc syndrome or retinoencephalofacial angiomatosis, is a rare non hereditory congenital phakomatosis. It is characterised by arteriovenous malformations (AVM's) of mid-brain,visualpathaway and facial nevi ${ }^{1}$.The presence of all three is not required for the diagnosis and there are numerous reports of patients in whom one or more characteristics are absent ${ }^{3}$.It usually is unilateral and often is asymptomatic. It has no age-sex-racial predilection. These combined vascular abnormalities are recognised prior to the reports of Bonnet $(1937)^{2}$ and Wyburn-Mason $(1943)^{1}$, But eponym derived from Wyburn -Mason, who studied this association in 27 patients with retinal AVMs in 1943 and found that $81 \%$ also possessed intracranial AVMs. ${ }^{1}$ The condition results from a disturbance in embryonic development of vascular mesoderm. ${ }^{4}$ Recognition of association between the retinal and intracranial lesions is important because it may allow early identification of intracranial AVM's and to decide further plan of action with intention to prevent future complications related to it.The most serious presentation includes headache,retroorbitalpain,hemiparesis,subarachnoidhaemorrhage due to rupture of AVM's. This patient presented with signs and symptoms due to rupture of intracranial AVM's. ${ }^{3}$

Case report : A 22 years old male patient,student,nonsmoker,non-hypertensive,non-diabetic,presented with weakness in right upper and lower limb since 3 days, which was sudden in onset, progressive over 3 days, associated with drooping of upper eyelid of right eye with deviation of angle of mouth to left side.This event was preceded by 1 episode of non-projectile vomitting and GTC seizure followed by a period of unconsciousness for 2-4 mins.Patient was drowsy but arousable( GCS was $\mathrm{E}_{3} \mathrm{M}_{5} \mathrm{~V}_{2}$ ), afebrile with stable vitals at the time of admission to the hospital. Patient was also having port wine coloured skin lesion over right side of the face (Fig 1) which was not crossing midline, a cutaneous menifestation involving facial skin.On neurological examination there was Hypotonia in right upper and lower limb with decreased power in the same $(2 / 5$ in right upper and lower limb).Plantar response was absent on right side.A fundus examination was done which revealed no signs of papilloedema, but there was venous dilatation with tourtuosity in left eye(Fig 2).Immediately SPIRAL CT BRAIN done which suggested a moderate sized ( 26 X $23 \mathrm{~mm}$ ) fresh haemorrhage in the left basal ganglia and deep periventricular region with minimal surrounding mass effect with extension seen in the ventricular system (Fig 2).CT ANGIOGRAPHY BRAIN revealed marked filling of the veins in the lesion with 
dilatation of internal cerebral vein ,suggestive of arterio-venous malformation on the left side. So in view of involvement of AVM's in retina ,brain and facial structure, it was diagnosed to have a case of Wyburn -Mason syndrome.

\section{Discussion}

Wyburn-Mason syndrome is a typically unilateral congenital entity,but bilateral cases have been reported $^{5-7}$ in which AVM's of retina ,mesencephalon and face coexist and originate from embryonary insult. ${ }^{8}$ The insult originates in the development of optic path. This process projects itself from mesencephalon to retina.This syndrome represents largest anterior plexus dysgenesia. ${ }^{8}$ The most common clinical findings are seizures in $32 \%$, haemorrhages with headache in $30 \%$ and hemiparesis in $50 \%$ of the cases. ${ }^{9}$ Neverthless ,the finding depends on extent of malformation. ${ }^{8}$

This is the first case of Wyburn-Mason syndrome that has been reported in our institution. This case presented all of the three main characteristics generally related to this syndrome.The correct diagnosis was supported by the initial clinical examination,the thorough neuro-ophthalmological examination and impressive findings on CT brain with angiography.

The treatment of this syndrome is still controversial.The first successful treatment combined intracranial resection,ligation of ophthalmic artery and selective arterial ligature of external carotid artery, was reported by Morgan in $1985 .{ }^{10}$ To determine the surgical approach,several factors should be considered including size of the malformation, its location whether it is in critical area or not ,neurological involvement( taking into account that neurological deficits are irreversible once established) and unknown natural history of AVM's. ${ }^{11}$

Conclusion : As in this case,congenital A-V malformation had lead to life threatening complication of intracranial haemorrhage at young age.surgical treatment was advised but could not be given because of denial by the patient.We wish to stress on early recognition of such AVM's and would be helpful in preventing a morbidity and mortality associated with this syndrome.

\section{References}

[1]. Wyburn-Mason R. Arteriovenous aneurysm of midbrain and retina, facial naevi and mental changes. Brain. 1943;66:163-203

[2]. Bonnet P, Dechaume J, Blanc E. L'aneurysmecirsoide de la retine (aneurysmevasemeaux). J Med Lyon.1937;18:165-178.

[3]. P.N.Dayani, A.A.Sadun. A case report of Wyburn-Mason syndrome and review of the literature.Case report. Neuroradiology (2007);49:445-456.

[4]. Selhorst JB. Phacomatoses. In: Miller NR, Newman NJ, eds. Walsh and Hoyt Clinical Neuro-Ophthalmology, $5^{\text {th }}$ ed. Baltimore:Williams and Wilkins, 1998:2725-9

[5]. Sibony PA, Lessell S, Wray S. Chiasmal syndrome caused by arteriovenous malformations. Arch Ophtalmol1982;100:438-442.

[6]. Hopen G, Smith JL, Hoff JT et al. The Wyburn-Mason syndrome.Concomitantchiasmal and fundus vascular malformations.JClinNeuroophtalmol1983;3:53-62.

[7]. Kim J, Kim OH, Suh JH, et al. Wyburn-Mason syndrome: an unusual presentation of bilateral orbital and unilateral brain arteriovenous malformations. PediatrRadiol1998;28:161.

[8]. Patel U, Gupta SC. Wyburn-Mason syndrome. A case report and review of literature. Neuroradiology 1990;31:544-546.

[9]. MacKenzie I. The clinical presentation of the cerebral angioma. A review of 50 cases. Brain 1953;76:184-214.

[10]. Morgan MK, Johnston IH, De Silva M. Treatment of opthalmofacial-hypothalamic arteriovenous malformation (BonnetDeschaume-Blanc syndrome). Case report. J Neurosurg 1985;63:794-796.

[11]. Lester J, Ruano-Calderón LA, González-Olhovich I.

[12]. Wyburn-Mason syndrome. J Neuroimaging 2005;15:284-285.

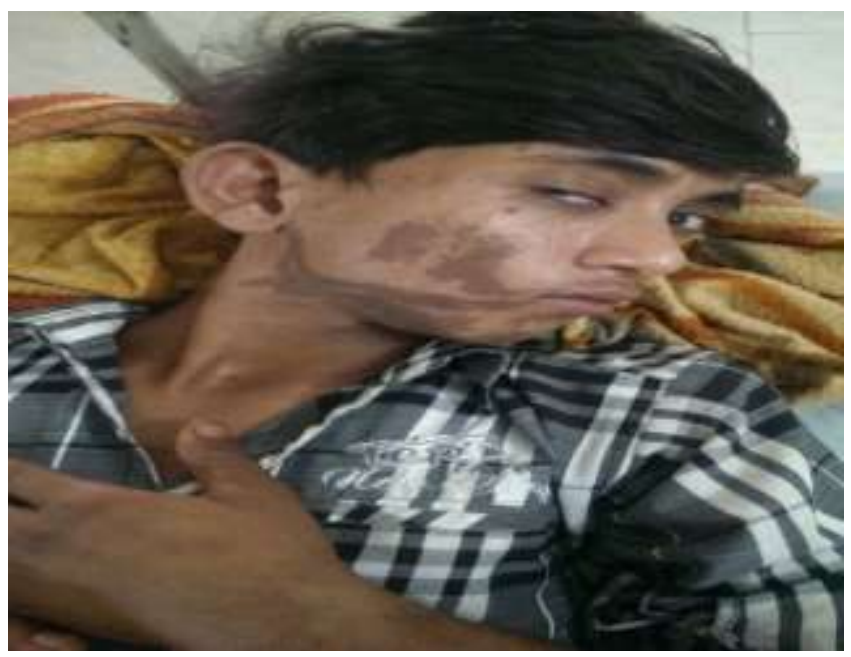

Fig 1. An actual picture of a patient Showing port wine coloured Skin lesion on right side of face. 


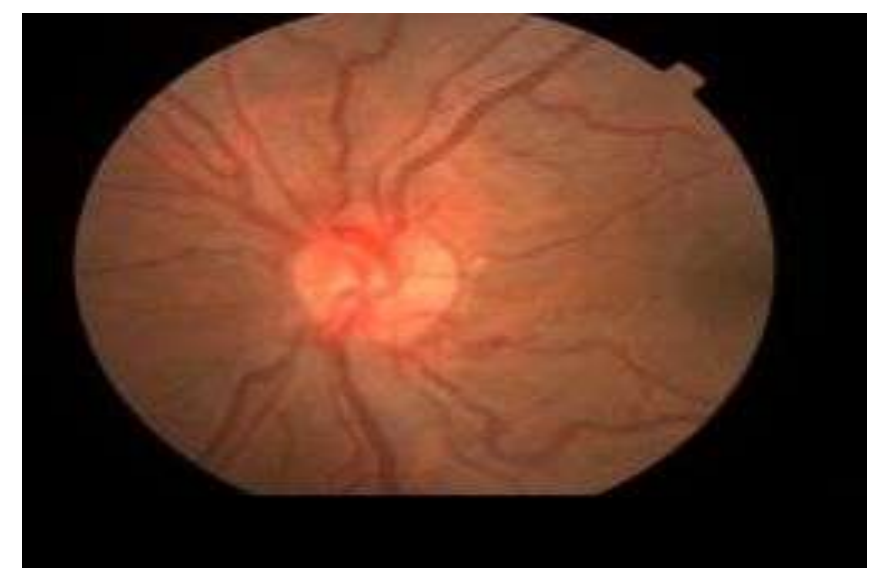

Fig 2. Fundus examination showing venous dilatation with tourtuosity in left eye

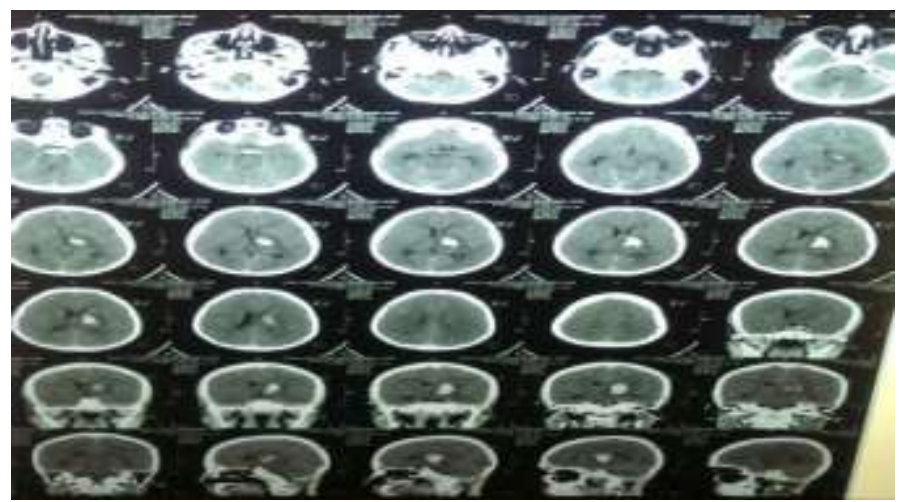

Fig 3. Spiral Computed tomography that clearly illustrated fresh haemorrhage in the left basal ganglia and deep periventricular region with minimal surrounding mass effect with extension seen in the ventricular system 